Didáctica. Lengua y literatura

ISSN-e: 1988-2548

https://dx.doi.org/10.5209/dida.65948

\title{
Quijote y fraseología: una propuesta para la enseñanza del español
}

\author{
Jacinto González Cobas ${ }^{1}$
}

Fecha revisión: 27-07-2018 / Fecha aceptación: 31-01-2019

Resumen. En los últimos años se ha abierto cierto debate en torno al uso de textos literarios en las clases de ELE, olvidados en gran parte en los primeros años del Enfoque comunicativo. Ello ha impedido el aprovechamiento didáctico de no pocas obras literarias, forma de actuación de la que no ha escapado el Quijote. Este artículo se inscribe en un marco en el que se considera que la literatura puede hacer interesantes aportaciones en el proceso de enseñanza/aprendizaje de idiomas. El Quijote genera curiosidad entre los aprendientes, permite la imbricación de la competencia lingüística y sociocultural, y constituye una importante muestra de unidades fraseológicas construidas con verbos de movimiento. En esta investigación se hacen algunas consideraciones sobre la presencia de la literatura en el aula de ELE, sobre el Quijote y la fraseología contenida en él, al tiempo que se presenta una propuesta didáctica (una caza del tesoro) para llevar al aula de ELE la figura de Cervantes, el Quijote y parte de la fraseología empleada en esta obra.

Palabras clave: caza del tesoro; ELE; fraseología; Quijote; unidades fraseológicas.

\section{[en] Quixote and phraseology: a proposal for teaching Spanish}

\begin{abstract}
In the past years a debate has been opened concerning the use of literary texts in the SFL lessons, mainly forgotten in the first years of the Communicative Approach. This has impeded the didactic exploitation of quite a few literary works, lines of action that the Quixote could not avoid. This article is part of a framework in which it is considered that literature can make interesting contributions in the process of teaching/learning languages. The Quixote generates curiosity among learners, it allows the imbrication of the linguistic and sociocultural competence and constitutes an important sample of phraseological units built with verbs of movement. In this research I make some considerations about the presence of literature in the SFL classroom, about the Quixote and the phraseology contained in it, while I present a didactic proposal (a treasure hunt) to bring the figure of Cervantes, the Quixote and part of the phraseology used in this work to the SFL class.
\end{abstract}

Keywords: treasure hunting; SFL; phraseology; Quixote; phraseological units.

\section{[fr] Quichotte et phraséologie: une proposition pour l'enseignement de l'espagnol}

Résumé. Dans les dernières années, il y a eu un certain débat sur l'emploi de textes littéraires dans les classes d'ELE, oubliés dans les premières années de l'Approche communicative. Cela a empêché de profiter au niveau didactique d'un nombre considéré d'ouvrages littéraires, y compris Don Quichotte. Cet article s'inscrit dans un cadre où l'on considère que la littérature peut faire d'intéressantes contributions au processsus d'enseignement/apprentissage des langues étrangères. Don Quichotte génére de la

\footnotetext{
$1 \quad$ Universidad Autónoma de Madrid jacinto.gonzalez@uam.es
} 
curiosité parmi les étudiants, permet l'imbrication de la compétence linguistique et socioculturelle, et constitue un important échantillon d'unités phraséologiques construites avec des verbes de mouvement. Dans cette recherche, on fait quelques considérations sur la présence de la littérature dans la classe d'ELE, sur Don Quichotte et la phraséologie qu'il contient, et on présente une proposition didactique (une chasse au trésor) pour apporter à la classe d'ELE la figure de Cervantès, Don Quichotte et une grande partie de la phraséologie utilisée dans cet ouvrage.

Mots-clés: chasse au trésor ; ELE ; phraséologie ; Don Quichotte ; unités phraséologiques.

Sumario. 1. Introducción. 2. Un breve recorrido histórico. 3. Fraseología y Quijote: formas de integración en el aula de ELE. 4. Propuesta didáctica. 5. Conclusiones. 6. Manuales consultados. 7. Bibliografía. 8. Anexo I. 9. Anexo II. 10. Anexo III.

Cómo citar: González Cobas, J. (2019). Quijote y fraseología: una propuesta para la enseñanza del español, Didáctica. Lengua y literatura, 31, 191-216.

\section{Introducción}

En los últimos años se ha producido cierta revalorización de los textos literarios en las clases de ELE, tras un extenso periodo en el que estos fueron rechazados o infrautilizados. Ello se debió a que se les identificó durante largo tiempo con el Método de Gramática-traducción, que hacía de este tipo de escritos el medio y el fin para el aprendizaje de lenguas. La potenciación de la oralidad por parte de los nuevos enfoques y métodos, así como la aparición de planteamientos pedagógicos que subrayaron la necesidad de utilizar materiales ligados a la cotidianidad inmediata contribuyeron a un alejamiento de esta suerte de textos. Reflejo de tal situación ha sido su escasa aparición en los manuales de ELE hasta hace no demasiado tiempo o su casi nula integración en los mismos. Ello ha impedido el aprovechamiento didáctico de no pocas obras literarias, que son una fuente muy rica de fenómenos de orden lingüístico, pragmático, cultural, etc. De esta forma de actuación no ha escapado una obra fundamental de la literatura española y universal como es el Quijote.

Este artículo se inscribe en un marco en el que se considera que la literatura puede hacer interesantes aportaciones en el proceso de enseñanza/aprendizaje de idiomas, incluso cuando se trata de obras escritas hace largo tiempo, pues existen fórmulas metodológicas para acercar este tipo de textos al alumnado de ELE. El Quijote, concretamente, genera curiosidad entre los aprendientes y permite la imbricación de la competencia lingüística y sociocultural. Además, constituye una muestra importante de unidades fraseológicas construidas con verbos de movimiento. Me propongo hacer algunas consideraciones de orden teórico sobre la presencia de la literatura en el aula de ELE, sobre el Quijote y sobre la fraseología contenida en él, así como presentar una propuesta didáctica para llevar al aula de ELE la figura de Cervantes, el Quijote y algunas muestras de la fraseología empleada en esta obra. 


\section{Un breve recorrido histórico}

La bibliografía centrada en la historia de los métodos y enfoques metodológicos ${ }^{2}$ coincide en que los textos literarios pasaron de tener un protagonismo absoluto en las clases de idiomas a prácticamente el ostracismo. Explica Nevado Fuentes (2015) que ya desde el Medievo la enseñanza de lenguas se basaba en el modelo latino, fundamentado en el análisis y traducción de textos literarios. Se consideraba que la mejor forma de acercarse a un idioma era hacerlo a través de sus producciones más prestigiosas. Ciertos cambios habidos en los siglos XVII y XVIII no alteraron esta concepción $^{3}$, y el posterior método conocido como tradicional o de Gramática y Traducción no hizo sino confirmar esta manera de encarar el proceso de enseñanza/aprendizaje de una L2. La memorización de listas de palabras, los ejercicios gramaticales de índole normativa y la traducción de textos literarios eran prácticas habituales.

La entrada en escena de los métodos estructurales, en la década de los 50, sí supuso una ruptura significativa respecto de la metodología que se había empleado anteriormente. Se dio primacía a la lengua oral y la literatura quedó prácticamente desterrada de los planes de estudio y de la praxis docente. Hubo un deseo de alejarse de las técnicas pedagógicas y los currículos que habían dominado hasta el momento, en los que la literatura era el medio y el fin perseguidos al mismo tiempo.

Los programas nociofuncionales no revirtieron la situación y, si bien se organizaron los contenidos a partir de parámetros nocionales y funcionales (Albaladejo, 2007), los textos literarios quedaron alejados de las aulas de idiomas o no tuvieron demasiada importancia.

En los años 80 nació el Enfoque comunicativo, y aspectos como la potenciación de la lengua oral, la motivación, dinámicas de aula o la negociación con el alumnado cobraron protagonismo. En este marco también quedaron excluidos, al menos en principio, los textos literarios, porque se consideraron alejados de la cotidianidad. Las producciones literarias fueron concebidas como artificiosas y difíciles de comprender para hablantes no nativos y, por ende, desmotivadoras. También se señaló, tal y como indica Millares (2003), que inducían a tratar cuestiones ajenas a los cursos generales de ELE, y que su adaptación para hacerlas más asequibles les hacía perder autenticidad.

En los últimos años ha habido cierta reacción que se ha reflejado en una bibliografía que presenta alegatos en pro del uso de textos literarios en las aulas de ELE. Si bien el mundo anglosajón ha sido pionero en este asunto ${ }^{4}$, en el caso del español como lengua extranjera la lista de autores que se alinean en esta posición va aumentando ${ }^{5}$. Estos defienden que los textos literarios son también realia; que reflejan un input de gran calidad; que tratan temas, en muchos casos, de alcance universal;

2 Vid. Richards y Rogers (2003), Sánchez (2009), Nevado Fuentes (2015) y García García y Álvarez López (2017).

3 Nevado Fuentes (2015) explica que ni la irrupción del Realismo pedagógico (movimiento surgido en el siglo XVII contra la educación del Humanismo) ni de la Ilustración consiguieron mover un ápice las convicciones existentes en esos periodos acerca de la enseñanza de idiomas.

4 Vid. Widdowson (1975), Collie y Slater (1987), Brumfit y Carter (1986) y Maley y Duff (1989, 1990).

5 Entre otros, Acquaroni (1997, 2006), Naranjo (1999), Sitman y Lerner (1999), Martín Peris (2000), Sanz Pastor (2000), San Mateo Valdehíta (2001), Millares (2003), Martínez Sallés (1999, 2004), Mendoza Fillola (2004), Sanz Pastor e Higueras García (2005), Albaladejo (2007), Ubach Medina (2008), González Cobas (2009, 2014), Iriarte Vañó (2009), Menouer Fouatih (2009), Stembert (2009), Alonso Cortés (2010), Garrido y Montesa (2010), Sanmartín Vélez (2010), Nevado Fuentes (2015), Gómez Sacristán y Madrigal López (2017) o Palacios (2017). 
que producen gran interactividad; que determinados subgéneros contienen construcciones y léxico que se repite en distintos pasajes, lo cual facilita su asimilación y fijación; que aportan contextos variados; que fomentan la activación de interpretación y de negociación de significados; que pueden ser un buen instrumento para incrementar la capacidad de distinguir entre significados literales y metafóricos; que motivan para la lectura; que hacen más creativos y arriesgados lingüísticamente a los aprendientes; que comprenderlos es motivo de satisfacción para los estudiantes; que admiten formas de explotación variadas y algunas de las técnicas didácticas más consolidadas entre los profesores de ELE; o que forman parte del acervo cultural de la lengua meta. A estos deben añadirse otros argumentos, como que un lector competente es aquel que es capaz de interpretar textos pertenecientes a un abanico amplio de géneros; que trabajar con textos literarios puede contribuir a fomentar cierto espíritu crítico en los discentes; que constituyen un elemento de innovación porque no se emplean en el día a día; y que activan un buen número de estrategias cognitivas, de memoria y afectivas.

Con respecto al aporte cultural, es importante señalar que en el Plan Curricular del Instituto Cervantes (2006) hay un inventario denominado "Referentes culturales" (y se incluye en él un apartado sobre "Literatura y pensamiento"), en el que se recogen las creencias, valores, representaciones y símbolos que inciden en la competencia intercultural, por tener la dimensión cultural una relación directa con la lengua en su proyección comunicativa. En el $\operatorname{MCER}(2002,60)$, por su parte, se afirma que "Las literaturas nacionales y regionales contribuyen de forma importante a la herencia cultural europea", y se alude a los textos literarios en el apartado "Usos estéticos de la lengua", si bien se señala que "Los estudios literarios cumplen muchos más fines educativos, intelectuales, morales, emocionales, lingüísticos y culturales que los puramente estéticos" (MCER, 2002, 60). Además, se hace referencia a ellos en los apartados referentes a la comprensión lectora y a la expresión escrita (trabajos literarios o reseñas de textos literarios), siempre ligados al nivel $\mathrm{C} 2$.

De todos modos, no son demasiados los textos literarios que encontramos en los manuales recientes de ELE, aunque en algunos casos sí se observa cierto cambio de tendencia respecto de años pasados. Los citados textos forman parte en ocasiones de una unidad o tema determinados (imbricados en estos últimos), aunque también aparecen en secciones de materiales complementarios o de repaso.

Un análisis de Agencia ELE, Bitácora nueva edición, ELE Actual, En Acción, Nuevo Español en Marcha y Nuevo Prisma en todos los niveles que han sido publicados arroja los siguientes resultados:

\section{Agencia $E L E$}

Cuadro 1. Textos literarios en Agencia ELE.

\begin{tabular}{|c|c|}
\hline Nivel & Número de textos literarios \\
\hline A1 & 0 \\
\hline A2 & 0 \\
\hline B1 & 0 \\
\hline B2 & 2 \\
\hline
\end{tabular}




\section{Bitácora nueva edición}

Cuadro 2. Textos literarios en Bitácora nueva edición.

\begin{tabular}{|c|c|}
\hline Nivel & Número de textos literarios \\
\hline A1 & 0 \\
\hline A2 & 1 \\
\hline B1 & 2 \\
\hline B2 & 3 \\
\hline
\end{tabular}

\section{ELE Actual}

Cuadro 3. Textos literarios en ELE Actual.

\begin{tabular}{|c|c|}
\hline Nivel & Número de textos literarios \\
\hline A1 & 0 \\
\hline A2 & 0 \\
\hline B1 & $7^{6}$ \\
\hline B2 & 9 \\
\hline
\end{tabular}

\section{En Acción}

Cuadro 4. Textos literarios en En Acción.

\begin{tabular}{|c|c|}
\hline Nivel & Número de textos literarios \\
\hline A1 & 0 \\
\hline A2 & 0 \\
\hline B1 & 3 \\
\hline B2 & 3 \\
\hline C1 & $7^{7}$ \\
\hline
\end{tabular}

\section{Nuevo Español en Marcha}

Cuadro 5. Textos literarios en Nuevo Español en Marcha.

\begin{tabular}{|c|c|}
\hline Nivel & Número de textos literarios \\
\hline A1 & 0 \\
\hline A2 & 0 \\
\hline B1 & 0 \\
\hline B2 & 4 \\
\hline
\end{tabular}

6 Todos ellos están ubicados, excepto un caso en que el texto en cuestión forma parte de la unidad, en la sección "Materiales complementarios" o en la de "Repaso".

7 Varios de ellos forman parte de la misma actividad. 


\section{Nuevo Prisma}

Cuadro 6. Textos literarios en Nuevo Prisma.

\begin{tabular}{|c|c|}
\hline Nivel & Número de textos literarios \\
\hline A1 & 0 \\
\hline A2 & 0 \\
\hline B1 + B2 & 0 \\
\hline C1 & 0 \\
\hline C2 & $9^{8}$ \\
\hline
\end{tabular}

Si tomamos como referencia los textos de etapas ya lejanas a la actual, podemos señalar que tan solo aparecen un fragmento (brevísimo) de El perro del hortelano de Lope de Vega en Nuevo Prisma C2 y una rima de Gustavo Adolfo Bécquer en ELE Actual B2.

En cuanto a actividades basadas en textos literarios o centradas en literatura publicadas en Internet, su presencia no es significativa si lo comparamos con otros tipos de textos o recursos. El análisis de cuatro webs de consulta frecuente por parte del profesorado de español como lengua extranjera (Formespa, MarcoELE, RutaELE y TodoELE) así lo demuestra:

\section{Formespa (http://formespa.rediris.es/)}

Cuadro 7. Actividades con textos literarios en Formespa.

\begin{tabular}{|c|c|c|}
\hline Nivel & Número total de actividades & Actividades con textos literarios \\
\hline A1-A2 & 99 & 2 (de A2) $(1,98 \%)$ \\
\hline B1-B2 & 75 & $4($ dos de $\mathrm{B} 1$ y dos de B2) (3\%) \\
\hline C1-C2 & 55 & $\begin{array}{l}5(4 \text { para los dos niveles y una específicamente para } \mathrm{C} 1) \\
(2,75 \%)\end{array}$ \\
\hline
\end{tabular}

\section{MarcoELE (http://marcoele.com/)}

Cuadro 8. Actividades con textos literarios en MarcoELE.

\begin{tabular}{|c|c|c|}
\hline Nivel & Número total de actividades & Actividades con textos literarios \\
\hline A1 & 24 & $0(0 \%)$ \\
\hline A2 & 45 & $0(0 \%)$ \\
\hline B1 & 70 & $2(1,4 \%)$ \\
\hline B2 & 72 & $5(3,6 \%)$ \\
\hline C1 & 56 & $13(7,28 \%)$ \\
\hline C2 & 73 & $3(2,1 \%)$ \\
\hline
\end{tabular}

8 Cinco de ellos son fragmentos muy cortos que forman parte de una misma actividad. 


\section{RutaELE (http://www.rutaele.es/)}

Cuadro 9. Actividades con textos literarios en RutaELE.

\begin{tabular}{|c|c|c|}
\hline Nivel & Número total de actividades & Actividades con textos literarios \\
\hline A1 & 46 & 0 \\
\hline A2 & 89 & 2 \\
\hline B1 & 121 & 2 \\
\hline B2 & 133 & 2 (una para los dos niveles y otra \\
\hline específicamente para C2)
\end{tabular}

TodoELE (http://www.todoele.net/) ${ }^{9}$

Cuadro 10. Actividades con textos literarios en TodoELE. ${ }^{10}$

\begin{tabular}{|c|c|c|}
\hline Nivel & $\begin{array}{c}\text { Número de actividades con textos } \\
\text { literarios según el nivel }{ }^{\mathbf{1 0}}\end{array}$ & $\begin{array}{c}\text { Número total de actividades con } \\
\text { textos literarios }\end{array}$ \\
\hline A1 & 1 & 76 \\
\hline A2 & $\begin{array}{c}\text { 2 (una de A2 y la otra para todos los } \\
\text { niveles, con adaptación de las diversas } \\
\text { actividades presentadas) }\end{array}$ & 76 \\
\hline B1 / B2 & 59 & 76 \\
\hline C1 / C2 & 28 & 76 \\
\hline
\end{tabular}

La atención prestada a los textos clásicos en estas páginas es significativamente menor que a los escritos en épocas o fechas más recientes:

\section{Formespa (http://formespa.rediris.es/)}

Cuadro 11. Actividades con textos literarios clásicos en Formespa.

\begin{tabular}{|c|c|c|}
\hline Nivel & $\begin{array}{c}\text { Número total actividades con textos } \\
\text { literarios }\end{array}$ & $\begin{array}{c}\text { Actividades con textos literarios } \\
\text { clásicos }\end{array}$ \\
\hline A1-A2 & 2 & 0 \\
\hline B1-B2 & 4 & 2 (las dos sobre el Quijote) \\
\hline C1-C2 & 5 & 2 (una sobre el Quijote) \\
\hline
\end{tabular}

9 En esta página web hay una sección llamada "Literatura y ELE" que es la que se ha consultado, por lo que aparecen mezclados todos los niveles para los que se proponen actividades basadas en textos literarios. Ello justifica que el número total de actividades basadas en textos literarios siempre sea el mismo: 76.

10 Es frecuente en esta página que se proponga una misma actividad para distintos niveles a partir de cierta adaptación (o no) de las propuestas didácticas en cuestión, por lo que a menudo se han contabilizado en casillas de distintos niveles las mismas actividades, y eso justifica que el número total de estas últimas no sea 76. 


\section{MarcoELE (http://marcoele.com/)}

Cuadro 12. Actividades con textos literarios clásicos en MarcoELE.

\begin{tabular}{|c|c|c|}
\hline Nivel & $\begin{array}{c}\text { Número total actividades con textos } \\
\text { literarios }\end{array}$ & $\begin{array}{c}\text { Actividades con textos literarios } \\
\text { clásicos }\end{array}$ \\
\hline A1 & 0 & 0 \\
\hline A2 & 0 & 0 \\
\hline B1 & 2 & 1 (sobre el Quijote) \\
\hline B2 & 5 & 1 \\
\hline C1 & 13 & 1 \\
\hline
\end{tabular}

\section{RutaELE (http://www.rutaele.es/)}

Cuadro 13. Actividades con textos literarios clásicos en RutaELE.

\begin{tabular}{|c|c|c|}
\hline Nivel & $\begin{array}{c}\text { Número total actividades con textos } \\
\text { literarios }\end{array}$ & $\begin{array}{c}\text { Actividades con textos literarios } \\
\text { clásicos }\end{array}$ \\
\hline A1 & 0 & 0 \\
\hline A2 & 2 & 0 \\
\hline B1 & 1 & 0 \\
\hline B2 & 2 & 0 \\
\hline C1 / C2 & 2 & 0 \\
\hline
\end{tabular}

TodoELE (http://www.todoele.net/)

Cuadro 14. Actividades con textos literarios clásicos en TodoELE.

\begin{tabular}{|c|c|c|}
\hline Nivel & $\begin{array}{c}\text { Número total actividades con textos } \\
\text { literarios }\end{array}$ & $\begin{array}{c}\text { Actividades con textos literarios } \\
\text { clásicos }\end{array}$ \\
\hline A1 & 1 & 0 \\
\hline A2 & 2 & 0 \\
\hline B1 /B2 & 59 & 1 (sobre el Quijote) \\
\hline C1 / C2 & 28 & 3 \\
\hline
\end{tabular}

Dentro de los textos clásicos al Quijote se le ha prestado cierta atención en las webs consultadas. Ello se constata también en que ha sido objeto de atención por parte de autores como Sanz Pastor (2005), Sanz Pastor e Higueras García (2005), González Cobas y Herrero Sanz (2009) o Gyöngyösiné Balogh et al. (2013).

En las investigaciones y propuestas que se han centrado en la obra cumbre de Cervantes encontramos formas variadas de explotación, entre las que se encuentran aspectos gramaticales (distinción entre ser y estar o uso de preposiciones), de orden léxico (por ejemplo, la adjetivación con que caracterizar a Don Quijote frente a Sancho Panza), o de índole cultural, dirigidas a avanzar en un mayor conocimiento por parte de los aprendientes de la figura y universo cervantinos. También se busca fomentar el interés por la lectura en la literatura de la lengua meta. Sin embargo, no abundan los 
planteamientos en los que a una explotación fundamentalmente de base cultural se le sume poner el foco en un aspecto lingüístico destacado de la obra en cuestión como es la fraseología, sobre todo si se tiene en cuenta su extraordinaria riqueza idiomática.

Bien es cierto que las dificultades para plantear ejercicios lingüísticos a partir de un texto clásico no son nada despreciables, pero puede merecer la pena intentar ciertas explotaciones para acercar de una manera más "auténtica" este tipo de textos al alumnado, sobre todo cuando este muestra intereses relacionados con la Historia, la literatura, etc.

Las unidades fraseológicas (UF) que aparecen en el Quijote se ponen en boca tanto del narrador y de personajes cultos como populares, y si bien muchas de ellas no han dejado rastro en la lengua actual (andar de zocos en colodros 'salir de un negocio peligroso y entrar en otro de mayor peligro'; andarse a la flor del berro 'darse al vicio y la ociosidad, entreteniéndose en una parte y en otra'; llevar la soga rastrando 'escapar pero estar aún en peligro evidente') ${ }^{11}$, otras (las que nos interesan) son hoy de uso frecuente. Me refiero a expresiones idiomáticas como andar a gatas, andar de mano en mano, caer en la cuenta, correr de boca en boca, ir a mesa puesta, llegar al alma, etc.

En estos casos se trata de UF construidas con verbos de movimiento (en las que se produce el paso de un movimiento real a uno figurado) o que acompañan con frecuencia a las UF, y no han recibido un tratamiento específico en la obra que nos ocupa, a pesar de que se trata de verbos de uso reiterado y que entran con frecuencia en este tipo de combinaciones.

A todos estos factores obedece la presentación de un listado de pautas de actuación que muestran cómo introducir Quijote y algunas cuestiones de fraseología en el aula de ELE, y de una propuesta didáctica que aúna explotación cultural y lingüística.

\section{Fraseología y Quijote: formas de integración en el aula de ELE}

La razón por la que fraseología y Quijote no se han interrelacionado hasta el momento en las clases de ELE ya se ha apuntado antes: la dificultad lingüística que puede representar para alumnos cuya lengua materna no es el español. Existen, no obstante, algunas fórmulas básicas metodológicas que pueden ayudar al profesor de ELE al respecto:

1. Explicación UF. El docente debe asegurarse de que los estudiantes saben qué es una unidad fraseológica y cuáles son sus rasgos definidores ${ }^{12}$. Se puede trabajar en clase la posibilidad o no de variación formal de estas construcciones, por ejemplo. Considero una buena práctica asegurarse, antes de enfrentarse a la realización de los ejercicios en cuestión, de que los alumnos conocen bien este concepto.

Todas ellas figuran en el Tesoro de la lengua castellana o española de Covarrubias.

Aunque en ocasiones el término unidad fraseológica abarca también colocaciones o fórmulas rutinarias, recomiendo centrarse en su definición más estrecha: unidades léxicas que presentan un significado que no es deducible de la suma de los significados de los elementos que las integran (andar manga por hombro, irse por las ramas...). Sobre las características de las UF, consúltense Corpas (1996), Serradilla (2004, 2014) o Montoro del Arco (2006). Acerca de la distinción entre locuciones y colocaciones, vid. Barrios Rodríguez (2015). Para aproximarse a la fraseología desde un punto de vista didáctico, véase Ruiz Gurillo (2002). 
2. Selección. Es muy importante escoger bien los textos que van a ser objeto de explotación, pues muchos de ellos pueden no ser comprensibles para los aprendientes en ciertos niveles de aprendizaje o si no se ha llevado a cabo una adecuada contextualización.

3. Sencillez de las actividades. No me refiero únicamente a las instrucciones y enunciados de los ejercicios, sino a la tarea en sí que se demanda. En este sentido, resulta muy interesante la apreciación de Iriarte (2009), según la cual cuanta más dificultad presenten los textos más sencillas han de ser las actividades que se planteen sobre los mismos.

4. Atractivo de las actividades. Sin duda, la dificultad a que se ha aludido puede verse mitigada, al menos parcialmente, con el diseño de ejercicios que pensemos que van a atraer a los estudiantes. Parafraseando el punto anterior, cuanta más dificultad presenten los textos más atractivas han de ser las actividades. Combinar la explotación de un texto como el Quijote con Internet o con recursos audiovisuales pueden ser buenas alternativas.

5. Casuística de actividades. La variedad está valorada positivamente en el ámbito de la didáctica, porque, entre otros aspectos, permite abarcar estilos diversos de aprendizaje. Además, si se considera que los aprendientes se enfrentan a cierto nivel de dificultad, tal premisa adquiere aún más relevancia. Por otro lado, el hecho de que las UF requieran para su enseñanza de acciones distintas (identificación, comprensión del significado, atención a la forma como se construyen y producción) hace necesario plantear ejercicios de naturaleza diversa.

6. Aprendizaje cooperativo. Ha alcanzado un desarrollo notable en los últimos años de la mano de autores como Johnson, Johnson y Holubec (1994), Littlewood (1996), Dörney y Malderez (1999), Zhang (2010), Sánchez Cuadrado (2010) o Suárez Guerrero (2011). Sin duda, constituye una dinámica muy interesante para solventar los problemas que puedan surgir en la resolución de las actividades y para que los discentes se enriquezcan en términos cognitivos, motivacionales o interpersonales.

7. Contextualización. Conviene tener muy en cuenta que han de proporcionarse contextos claros y suficientes. Así debe actuarse con el léxico en general, pero más si cabe con las UF, por tratarse de construcciones opacas.

8. Aprendizaje inductivo. Sin menospreciar las fórmulas de aprendizaje deductivo, en un caso como el que nos ocupa puede resultar especialmente interesante hacer partícipes a los estudiantes, lo máximo posible, de su proceso de aprendizaje, de manera que ellos descubran por sí mismos la materia en cuestión.

\section{Propuesta didáctica}

Son muchas las posibilidades que tiene el docente para llevar al aula un texto como el Quijote. En este caso he optado por una caza del tesoro, por su carácter motivador y porque permite la integración de todas las destrezas y supone la inclusión en el aula de una tarea que los estudiantes no llevan a cabo asiduamente ${ }^{13}$.

13 Puede consultarse la caza del tesoro en cuestión en la dirección electrónica http://jacintogonzalezcobas.es/. 
Asimismo es un recurso que fomenta la implicación y autonomía de los alumnos en el proceso de aprendizaje, al tiempo que permite realizar fácilmente cambios en su diseño y contenido en función de la retroalimentación obtenida en el momento de su pilotaje.

Las cazas del tesoro son hojas de trabajo o páginas web que recogen una serie de preguntas cuyas respuestas han de ser buscadas en un listado de direcciones de Internet que se proporciona a los alumnos ${ }^{14}$. Su estructura es siempre la misma: una introducción que recoge las instrucciones que se dan al aprendiz para realizar el ejercicio que se propone; un cuestionario que incluye una serie de preguntas de mayor o menor complejidad; una lista de recursos que contiene direcciones de Internet que han de consultarse para contestar a las preguntas; la gran pregunta, cuya respuesta requiere integrar, relacionar y valorar lo aprendido durante las búsquedas; y la forma de evaluación.

Se pretende que los estudiantes realicen cierta labor de búsqueda, investigación y reflexión, activándose dinámicas cooperativas provechosas para su progreso en la materia, altamente motivadoras y que contribuyen a crear una atmósfera de colaboración muy interesante en términos pedagógicos. En el caso que nos ocupa, se han perseguido objetivos de variado signo, que compatibilizan aspectos fundamentalmente culturales con otros de orden lingüístico.

El apartado Introducción constituye un marco para las tareas que se va a pedir que hagan los aprendientes y contribuye a fomentar la motivación, al tiempo que se les hace saber que van a trabajar de manera cooperativa, lo cual implica la activación de ciertas formas de negociación y de interacción.

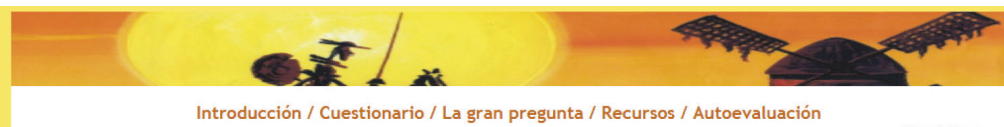

Introducción / Cuestionario / La gran pregunta / Recursos / Autoevaluación

Español como Lengua Extraniera Nivel CAcorce

Un viaje al Quijote
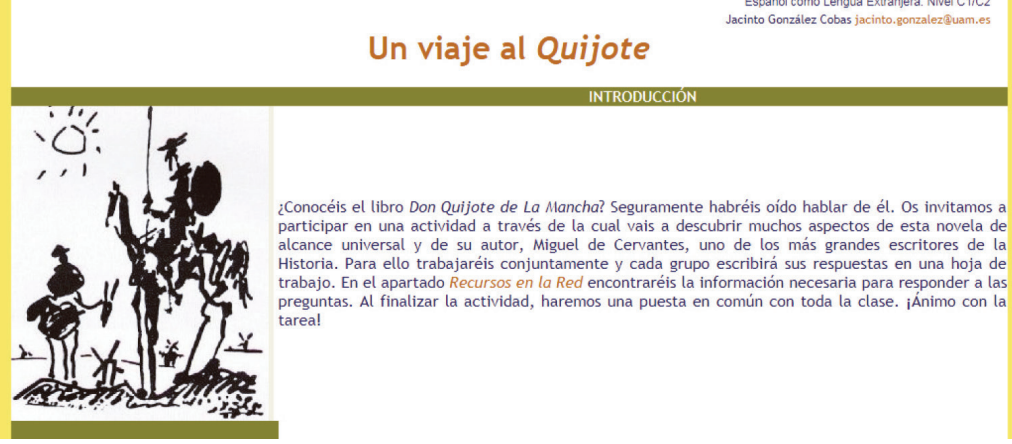

Con respecto al Cuestionario, en él se incluyen preguntas organizadas en torno a tres bloques temáticos: "Sobre el autor y la obra", "Sobre el Quijote" y "Expresiones idiomáticas". Con el primer bloque se pretende que el alumno conozca datos importantes para contextualizar el Quijote y la figura de Cervantes a partir del visionado de un vídeo de corta duración. 


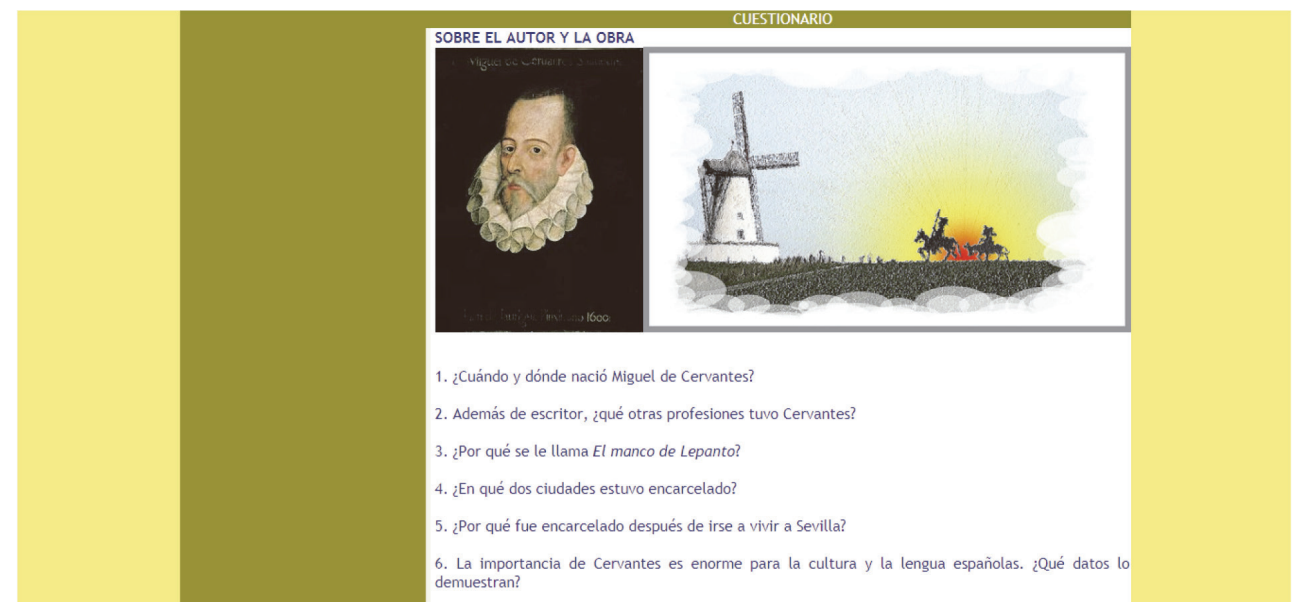

Mediante el segundo bloque se persigue que el estudiante conozca el comienzo del Quijote (que figura incluso en el Plan Curricular del Instituto Cervantes, en la sección "Referentes culturales") y que reflexione acerca de frases famosas de otros libros. También que conozca el argumento (bastante resumido) de la obra, el cual puede proporcionarle ciertas claves para su interpretación (ANEXo $I^{15}$ ), así como el episodio más conocido de la novela en cuestión (el de los molinos de viento) a partir de la lectura de la versión de Andrés Trapiello ${ }^{16}$. Asimismo se busca que realice ejercicios de comprensión lectora a propósito del citado episodio (ANEXo II) y que investigue la transcendencia de esta obra en manifestaciones artísticas y culturales de todo tipo: cuadros, grabados, música, películas, etc. La realización de estas actividades permitirá al alumno, además, comprender plenamente el significado de expresiones como ser un quijote o luchar contra molinos de viento, vinculadas de manera directa a la obra que nos ocupa.

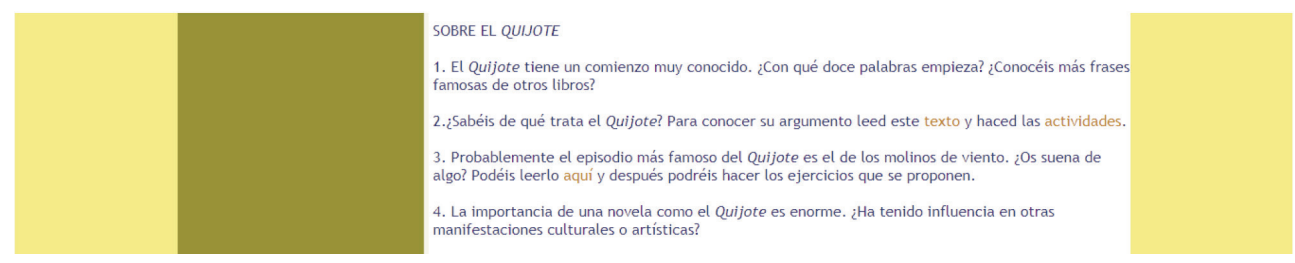

Por su parte, el bloque "Expresiones idiomáticas" tiene como objetivo centrar la atención del aprendiente en un aspecto lingüístico de esta novela: la fraseología. Ya se ha explicado que el Quijote atesora una extraordinaria riqueza idiomática, y con los ejercicios que se proponen el estudiante puede aprender o afianzar el conocimiento de algunas de ellas tomando como referencia algunos de sus pasajes.

15 A los tres anexos que se incluyen en este artículo se accede en la caza del tesoro en cuestión a través de sendos hipervínculos.

16 Don Quijote de La Mancha. Puesto en castellano actual íntegra y fielmente por Andrés Trapiello, Barcelona, Destino, 2015. Se trata de una versión que actualiza el lenguaje, pero preserva el espíritu de la obra. En estos términos lo expresa Mario Vargas Llosa en el prólogo: "En la versión de Trapiello la obra de Cervantes se ha rejuvenecido y actualizado, sin dejar de ser ella misma, poniéndose al alcance de muchos lectores”. 
Por otro lado, los ejercicios que se plantean para trabajar las UF (ANEXO III) han sido confeccionados partiendo de la premisa de que es necesario abordar distintos frentes en lo relativo a esta cuestión. Así, la primera actividad está dirigida a activar o reactivar en los alumnos el concepto de unidad fraseológica y a que reflexionen acerca de lo que ya saben al respecto y de las UF que usan en sus respectivas lenguas maternas. Con la segunda se busca que ellos mismos interpreten, a partir de ciertos pasajes, el significado de las expresiones idiomáticas resaltadas en cursiva. La dificultad que pudiera acarrear esta tarea se atenúa al ser presentadas las UF junto a una serie de definiciones que los aprendientes han de relacionar. Con el ejercicio 3 se persigue que los estudiantes reflexionen sobre la forma como se construyen las UF en cuestión. El ejercicio 4 tiene como meta que se asocien esas UF a ciertas situaciones de uso. Y la actividad 5 tiene como objetivo claro una producción de carácter libre.

Por otro lado, tras el cuestionario figura, en las cazas del tesoro, la sección La gran pregunta. Se ha optado por centrar la atención en la humanidad de don Quijote, pues los estudiantes deben reflexionar acerca de por qué, a pesar de su locura, don Quijote es percibido como un personaje muy humano y que genera gran simpatía.

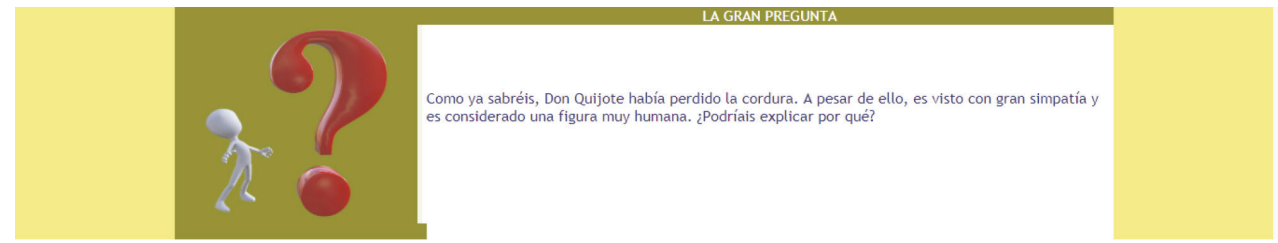

El apartado Recursos en la Red recoge un listado de direcciones electrónicas que ayuda a los estudiantes a la resolución de las tareas. Responde a la voluntad de presentar a aquellos una nómina fiable de sitios web, además de agilizar la labor de búsqueda de información y la realización de las actividades. En esa relación de páginas web, organizada en función de los bloques temáticos distinguidos anteriormente para facilitar la tarea a los aprendientes, figuran dos textos escritos y un archivo que incorpora la competencia audiovisual. Con ello se potencia la integración de las destrezas y se consigue que haya cierta diversidad en el planteamiento y en los objetivos de los ejercicios. Se ha procurado, por otro lado, que el número de documentos que los aprendientes han de manejar sea reducido, con la finalidad de que la caza del tesoro sea más fácil de llevar al aula.

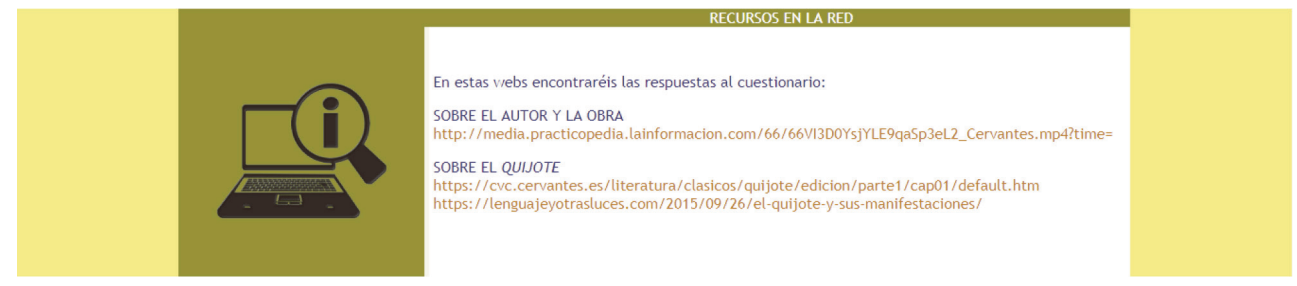


Por último, las cazas del tesoro contienen una sección relativa a la forma como será evaluada la actividad. La decisión de alterar el formato para dar cabida a una autoevaluación responde a la convicción de que ello responde mejor a las dinámicas de las aulas de ELE, en las que se insiste más en los avances que supone determinada actividad en el proceso de aprendizaje de la lengua meta que en una posible evaluación del estudiante (con una calificación concreta) a partir de la misma.

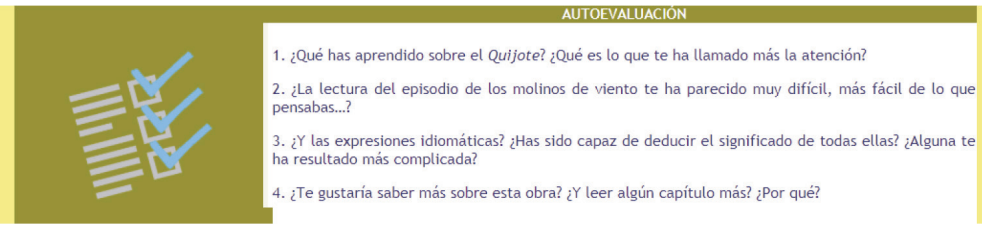

\section{Conclusiones}

A lo largo de estas páginas me he decantado por el uso de textos literarios en las clases de ELE, porque su no inclusión en los currículos o en la nómina de recursos utilizados por los docentes pudo deberse más a un deseo de distanciarse de las premisas metodológicas puestas en práctica en el método tradicional que a un debate sosegado acerca de las ventajas e inconvenientes que podría representar su uso. Mi apuesta es clara: no debemos cerrar las puertas a determinadas prácticas didácticas por el mero hecho de que estas se identifiquen con modelos pedagógicos que no se consideran adecuados o porque se quieran sortear ciertos niveles de dificultad. Es necesario estudiar profundamente los postulados que subyacen a las mismas, contextualizarlas convenientemente y analizar qué hay de provechoso en cada una de ellas. Al fin y al cabo, esta es la fórmula que permite mejorar los procesos de enseñanza y aprendizaje, y avanzar, de manera decidida, a cualquier disciplina.

Los textos literarios clásicos pueden contribuir a acercar la realidad cultural a los aprendientes de una L2 y hacer posible que estos comprendan cuestiones complejas relacionadas con la lengua o con la Historia de los pueblos en los que se habla el idioma que están en vías de aprender. La huella dejada por el Quijote en la cultura española es un buen motivo para dedicarle un espacio en las clases de ELE. Una de las formas de vencer las dificultades que puedan acarrear su inclusión en el currículum de una clase concreta es buscar actividades y proyectos motivadores. Para ello han de tenerse en cuenta diversos factores, pero a priori las cazas del tesoro, que permiten integrar todas las destrezas y son especialmente aptas para el trabajo cooperativo, representan una buena opción. Además, el uso que se hace de Internet cuando se resuelven cazas del tesoro supone poner las TIC al servicio del estudiante y del profesor como medio para alcanzar ciertos objetivos, muy lejos de su empleo como fin en sí mismo, tan desaconsejable en términos metodológicos.

Por último, el Quijote es una fuente muy rica de unidades fraseológicas, cuya enseñanza se ha revalorizado significativamente en los últimos años en el ámbito de ELE. A ello obedece la inclusión de una serie de actividades con las que se persigue conjugar el estudio y aprendizaje de este tipo de unidades léxicas con la obra cumbre cervantina. 


\section{Manuales consultados}

agencia ELE. Niveles A1, A2, B1 y B2, Madrid, SGEL.

Bitácora nueva edición. Niveles A1, A2, B1 y B2, Barcelona, Difusión.

ELE Actual. Niveles A1, A2, B1 y B2, Madrid, SM.

En Acción. Niveles A1, A2, B1, B2 y C1, Madrid, enClave-ELE.

Nuevo Español en Marcha. Niveles A1, A2, B1 y B2, Madrid, SGEL.

Nuevo Prisma. Niveles A1, A2, B1+B2, C1 y C2, Madrid, Edinumen.

\section{BIBLIOGRAFÍA}

Acquaroni, Rosana (1997): "La experiencia de la poesía en E/LE (o cómo llenar de columpios la clase de gramática)", Frecuencia L, 4, 17-20.

Acquaroni, Rosana (2006): "Hija del azar, fruto del cálculo: la poesía en el aula de E/LE", Carabela, 59, 49-77.

Albaladejo García, María Dolores (2007): “Cómo llevar la literatura al aula de ELE: de la teoría a la práctica" [en línea], MarcoELE, 5, 1-51. https://marcoele.com/descargas/5/albaladejo-literaturaalaula.pdf [Consulta: 3 marzo 2018].

Alonso Cortés, Teresa (2010): "El tratamiento del texto literario en el aula de ELE” [en línea], en Actas de las II Jornadas de Formación del Profesorado de español 2009 Sofía (Bulgaria), Barrio Barrio, J. F. (coord.), Sofía, Secretaría General Técnica del Ministerio de Educación, 3-11. http://redined.mecd.gob.es/xmlui/bitstream/handle/11162/81543/008201130129\%2060.pdf?sequence=1 [Consulta: 6 marzo 2018].

Barrios Rodríguez, María Auxiliadora (2015): Las colocaciones del español, Madrid, Arco/ Libros.

BrumFIT, Christopher J. y Ronald A. Carter (1986) (eds.): Literature and Language Teaching, Oxford, Oxford University Press.

Collie, Joanne y Stephen Slater (1987): Literature in the Language Classroom, Cambridge, Cambridge University Press.

Consejo de Europa (2002): Marco común de referencia para las lenguas: aprendizaje, enseñanza y evaluación [en línea], Madrid, Secretaría General Técnica del MECD-Subdirección General de Información y Publicaciones y Grupo Anaya. http://cvc.cervantes.es/ensenanza/biblioteca_ele/marco/cvc_mer.pdf [Consulta: 2 marzo 2018].

Corpas Pastor, Gloria (1996): Manual de fraseología española, Madrid, Gredos.

Covarrubias, Sebastián de (1611): Tesoro de la lengua castellana o española, ed. de F. C. R. Maldonado, revisada por M. Camarero, Madrid, Castalia, 1995.

Dörnyei, Z. y A. Malderez (1999): "The Role of Group Dynamics in Foreign Language Learning and Teaching", en Affect in Language Learning, ARnold, J. (ed.), Cambridge, Cambridge University Press, 155-169.

Fernández García, Alfonso (2005): "El texto literario en el aula de ELE. El Quijote como referencia (I)" [en línea], en La competencia pragmática y la enseñanza del español como lengua extranjera, Actas del XVI Congreso Internacional de ASELE, ÁlvareZ, A. et al. (eds.), Oviedo, Ediciones de la Universidad de Oviedo, 63-67. http://cvc.cervantes.es/ ensenanza/biblioteca_ele/asele/asele_xvi.htm [Consulta: 6 marzo 2018].

García García, Marta y Fátima Álvarez López (2017): “Enfoques y métodos en la enseñanza de ELE", en Manual del profesor de ELE, Cestero Mancera, A. M. y Penadés Martínez, I. (eds.), Alcalá de Henares, Servicio de Publicaciones Universidad de Alcalá, 521-599. 
Garrido, Antonio y Salvador Montesa (2010): "La recuperación de la literatura en la enseñanza del español como lengua extranjera. Una necesidad y una propuesta" [en línea], MarcoELE, 11, 384-396. http://marcoele.com/descargas/navas/19.garrido-montesa.pdf [Consulta: 2 febrero 2018].

González Cobas, Jacinto y Elena Herrero Sanz (2009): “El Quijote en la clase de ELE. Una propuesta didáctica" [en línea], Espéculo, 42. https://pendientedemigracion.ucm.es/info/ especulo/numero42/quiele.html [Consulta: 6 febrero 2018].

González Cobas, Jacinto (2012): "Internet en la clase de Lengua y literatura. Usos y estrategias didácticas" [en línea], Edutec-e, 40, 1-21. http://www.edutec.es/revista/index.php/ edutec-e/article/view/368 [Consulta: 8 marzo 2018], DOI: https://doi.org/10.21556/edutec.2012.40.368.

González Cobas, Jacinto y Ana Serradilla Castaño (2013): “Unidades fraseológicas con verbos de movimiento. Propuestas para un diccionario" [en línea], CLAC, 54, 7-43. http:// pendientedemigracion.ucm.es/info/circulo/no54/gonzalez.pdf [Consulta: 20 abril 2018], DOI: http://dx.doi.org/10.5209/rev_CLAC.2013.v54.42371.

González Cobas, Jacinto (2014): “Cómo, por qué y para qué usar microrrelatos en la enseñanza de ELE” [en línea], en ¿Qué necesitamos en el aula de ELE?: reflexiones en torno a la teoría y la práctica, González Cobas, J.; Serradilla Castaño, A.; Alonso Zarza, M. Á.; Pazó Espinosa, J. y García González, J. (eds.), vol. monográfico RedELE, 99-129. https:// www.mecd.gob.es/dam/jcr:b1 ffb304-2261-4eb1-8d7f-bc29638300f3/libro-completouam-pdf.pdf [Consulta: 10 mayo 2018].

Gómez Sacristán, Ma Luisa y Ma Jesús Madrigal López (2017): “El componente lúdico y la literatura en la clase de ELE", en Manual del profesor de ELE, Cestero Mancera, A. M. y Penadés Martínez, I. (eds.), Alcalá de Henares, Servicio de Publicaciones Universidad de Alcalá, 757-810.

Gyöngyösiné Balogh, Emese; Horváth, Alexandra y Barnabás Rız (2013): “Literatura y adaptaciones en la clase de ELE" [en línea], en Actas del I Congreso Internacional de Didáctica de Español como Lengua Extranjera del Instituto Cervantes de Budapest, Blas Nieves, Amelia et al. (eds.). https://docplayer.es/63124596-Literatura-y-adaptaciones-en-laclase-de-ele.html [Consulta: 10 mayo 2018].

Hernando Cuadrado, Luis Alberto (1997): "Sobre la fraseología del Quijote" [en línea], en El español como lengua extranjera: del pasado al futuro: Actas del VIII Congreso Internacional de ASELE, Moreno, F. (dir.) et al., Alcalá de Henares, Servicio de Publicaciones Universidad de Alcalá, 445-453. https://cvc.cervantes.es/ensenanza/biblioteca_ele/asele/ pdf/08/08_0443.pdf [Consulta: 6 marzo 2018].

Instituto Cervantes (2006): Plan Curricular del Instituto Cervantes. Niveles de referencia para el español [en línea], Madrid, Instituto Cervantes y Biblioteca Nueva. https://cvc. cervantes.es/ensenanza/biblioteca_ele/plan_curricular/default.htm [Consulta: 2 marzo 2018].

Johnson, David W.; Johnson, Roger T. y Edythe Holubec J. (1994): Cooperative Learning in the Classroom, Virginia, Association for Supervision and Curriculum Development (Trad. El aprendizaje cooperativo, Buenos Aires, Paidós, 1999).

Iriarte Vañó, M a Dolores (2009): "Cómo trabajar con textos literarios en el aula de ELE" [en línea], Tinkuy, 11, 187-206. file://D:/Usuarios/JG.5026689/Downloads/Dialnet-ComoTrabajarConTextosLiterariosEnElAulaDeELE-3303936\%20(7).pdf [Consulta: 6 abril 2018].

Littlewood, William (1996): La enseñanza comunicativa de idiomas. Introducción al enfoque comunicativo, Madrid, Edinumen. 
Maley, A. y A. Duff (1989): The Inwrad Ear. Poetry in the Laguage Classroom, Cambridge, Cambridge University Press.

Maley, A. y A. Duff (1990): Literature, Oxford, Oxford University Press.

Martín Peris, Ernesto (2000): “Textos literarios y manuales de enseñanza de español como lengua extranjera" [en línea], Lenguaje y textos, 16, 101-130. http://ruc.udc.es/dspace/ bitstream/2183/8128/1/LYT_16_2000_art_9.pdf [Consulta: 8 febrero 2018].

Martínez Sallés, Matilde (1999): "Los retos pendientes en la didáctica de la literatura en ELE"[en línea],Mosaico,3, 19-22.file:///D:/Usuarios/JG.5026689/Downloads/13137_19. pdf [Consulta: 9 febrero 2018].

Martínez Sallés, Matilde (2004): “«Libro, déjame libre». Acercarse a la literatura con todos los sentidos”[enlínea],RedELE,0.http://www.mecd.gob.es/dam/jcr:c9b5bc95-4388-4bca-972c5dcb352f5ec6/2004-redele-0-19martinez-salles-pdf.pdf [Consulta: 20 marzo 2018].

Mendoza Fillola, Antonio (2004): "Los materiales literarios en la enseñanza de ELE: funciones y proyección comunicativa" [en línea], RedELE, 1. http://redined.mecd.gob.es/xmlui/ bitstream/handle/11162/72234/00820083000349.pdf?sequence=1\&isAllowed=y $\quad$ Consulta: 20 marzo 2018].

Menouer Fouatih, Wahiba (2009): "La literatura como recurso didáctico en el aula de E/LE" [en línea], en Actas del Taller "Literaturas hispánicas y ELE”, Díez Plaza, C. L. et al. (eds.), Orán, Instituto Cervantes de Orán, 121-130. https://cvc.cervantes.es/ensenanza/ biblioteca_ele/publicaciones_centros/PDF/oran_2009/13_fouatih.pdf [Consulta: 21 marzo 2018].

Millares, Selena (2003): "Función didáctica de la literatura en la enseñanza de una segunda lengua", Frecuencia L, 22, 41-45.

Montoro del Arco, Esteban Tomás (2006): Teoría fraseológica de las locuciones particulares, Frankfurt, Peter Lang.

Naranjo, María (1999): La poesía como instrumento didáctico en el aula de español como lengua extranjera, Madrid, Edinumen.

Núñez Ramos, Rafael (2005): "El texto literario en el aula de ELE. El Quijote como referencia (II)" [en línea], en La competencia pragmática y la enseñanza del español como lengua extranjera, Actas del XVI Congreso Internacional de ASELE, Álvarez, A. et al. (eds.), Oviedo, Ediciones de la Universidad de Oviedo, 67-76. https://cvc.cervantes.es/ensenanza/biblioteca_ele/asele/pdf/16/16_0067.pdf [Consulta: 21 marzo 2018].

Nevado Fuentes, Charo (2015): "El texto literario en las clases de ELE: un recurso didáctico y motivador" [en línea], Revista Internacional de Lenguas Extranjeras, 4, 151-161. file://D:/Usuarios/JG.5026689/Downloads/701-2667-1-PB.pdf [Consulta: 19 abril 2018], DOI: 10.17345/rile2015151-167.

Palacios González, Sergio (2017): Los textos literarios clásicos en la enseñanza-aprendizaje del español como segunda lengua (L2) / lengua extranjera: estudio, corpus, propuesta didáctica y puesta en práctica para los niveles A1-A2. Tesis doctoral inédita, Universidad Autónoma de Madrid.

Real Academia Española y ASALE (2010): Nueva gramática de la lengua española. Manual, Madrid, Espasa.

Richards, Jack C. y Theodore S. Rodgers (2003, $2^{\mathrm{a}}$ ed.): Enfoques y métodos en la enseñanza de idiomas, Madrid, Edinumen.

Ruiz Gurillo, Leonor (2002): Ejercicios de fraseología, Madrid, Arco/Libros.

Ruiz Martínez, Ana $\mathrm{M}^{\mathrm{a}}$ (2006): "La enseñanza de locuciones a través del Quijote" [en línea], RedELE, 8. http://redined.mecd.gob.es/xmlui/bitstream/handle/11162/72140/00820083000264.pdf?sequence=1\&isAllowed=y [Consulta: 12 abril 2018]. 
San Mateo Valdehíta, Alicia (2001): "Herramientas para utilizar un texto narrativo extenso como eje estructurador o material de apoyo de un curso de E/LE", Frecuencia L, 17, pp. 17-22.

Sánchez, Aquilino (2009): La enseñanza de idiomas en los últimos cien años. Métodos y enfoques, Madrid, SGEL.

Sánchez Cuadrado, Adolfo Manuel (2010): "La química y el aula de E/LE. Dinámica de grupos y atención a la dimensión social del aula de idiomas" [en línea], MarcoELE, 10, 117-128. http://marcoele.com/descargas/expolingua_2006.sanchez.pdf [Consulta: 6 mayo 2018].

Sánchez Jiménez, Santiago U. (2011): “Andanzas del verbo andar”, en Tiempo, espacio y relaciones espacio-temporales desde la perspectiva de la lingüística histórica, Sinner, C. et al. (coords.), Logroño, Cilengua, 227-264.

Sanmartín Vélez, Juana (2010): "La literatura en la clase de E/LE: objetivos y actividades" [en línea], en Del texto a la lengua: la aplicación de los textos a la enseñanza-aprendizaje del español L2-LE. Actas del XXI Congreso Internacional ASELE, De Santiago Guervós, J. et al. (eds.), Salamanca, ASELE, vol. II, 793-804. http:/cvc.cervantes.es/ensenanza/biblioteca_ele/asele/pdf/21/21_0793.pdf [Consulta: 11 abril 2018].

Sanz Pastor, Marta (2000): "La literatura en el aula de ELE", Frecuencia L, 14, pp. 24-27.

Sanz Pastor, Marta (2005): "El Quijote, un crisol didáctico para el encuentro de la lengua, la cultura y el discurso" [en línea], Mosaico, 15, file://D:/Usuarios/JG.5026689/Downloads/13149_19.pdf [Consulta: 6 mayo 2018].

Sanz Pastor, Marta y Marta Higueras García (2005) [en línea]: “Una propuesta didáctica a través del Quijote», en La competencia pragmática y la enseñanza del español como lengua extranjera, Actas del XVI Congreso Internacional de ASELE, Álvarez, A. et al. (eds.), Oviedo, Ediciones de la Universidad de Oviedo, 817-824. https://cvc.cervantes.es/ ensenanza/biblioteca_ele/asele/pdf/16/16_0817.pdf [Consulta: 21 marzo 2018].

Serradilla Castaño, Ana (2004): "Ir y caer como constituyentes de locuciones fraseológicas que no implican movimiento", Verba Hispánica, XII, 131-141, DOI: https://doi. org/10.4312/vh.12.1.131-141.

Serradilla Castaño, Ana (2014): "La fraseología en el aula de ELE: nuevos enfoques y propuestas didácticas" [en línea], en Qué necesitamos en el aula de ELE: reflexiones en torno a la teoría y la práctica, González Cobas, J.; Serradilla Castaño, A.; Alonso Zarza, M. Á.; Pazó Espinosa, J. y García González, J. (eds.), RedELE, vol. monográfico, 73-98. https:// www.mecd.gob.es/dam/jcr:b1 ffb304-2261-4eb1-8d7f-bc29638300f3/libro-completouam-pdf.pdf [Consulta: 10 mayo 2018].

Serradilla Castaño, Ana y Jacinto González Cobas (2017): “Unidades fraseológicas con verbos de movimiento en el Quijote: un acercamiento a la lengua real de la época" [en línea], Paremia, 26, 41-54. https://cvc.cervantes.es/lengua/paremia/pdf/026/004_serradilla-gonzalez.pdf [Consulta: 9 abril 2018].

Serradilla Castaño, Ana (2019): “Andando de zoca en colodra: las unidades fraseológicas con verbos de movimiento en la obra de Cervantes", Onomázein, 43, 181-199.

Sitman, Rosalie e Ivonne Lerner (1999): "La literatura del mundo hispanohablante en el aula de ELE: ¿un lugar de encuentro o desencuentro?” [en línea], Espéculo, 12. http://www. ucm.es/info/especulo/numero12/cbelatxt.html [Consulta: 7 marzo 2018].

Soler-Espiauba, Dolores (2005): "El texto literario en el aula de ELE. El Quijote como referencia (III)" [en línea], en La competencia pragmática y la enseñanza del español como lengua extranjera. Actas del XVI Congreso Internacional de ASELE, Álvarez, A. et al., Oviedo, Ediciones de la Universidad de Oviedo, 77-87. https://cvc.cervantes.es/ensenanza/biblioteca_ele/asele/pdf/16/16_0077.pdf [Consulta: 21 marzo 2018]. 
Stembert, Rudolf (2009): "Propuestas didácticas de los textos literarios en la clase de E/LE" [en línea], MarcoELE, 9, 247-265. http://marcoele.com/descargas/expolingua_1999.stembert.pdf [Consulta: 7 abril 2018].

Suárez Guerrero, Cristóbal (2011): "Interacción virtual y aprendizaje cooperativo. Un estudio cualitativo", Revista de Educación, 354, 473-498.

Ubach Medina, Antonio (2008): "El texto literario en la clase de ELE: propuesta de métodos de evaluación" [en línea], en La evaluación en el aprendizaje y la enseñanza del español como lengua extranjera / segunda lengua: XVIII Congreso Internacional de la Asociación para la Enseñanza del Español como lengua Extranjera (ASELE), PASTOR CESTERos, S. y Roca Marín, S. (coords.), Alicante, Universidad de Alicante, 586-589. file://D:/ Usuarios/JG.5026689/Downloads/Dialnet-ElTextoLiterarioEnLaClaseDeELE-3192767. pdf [Consulta: 2 abril 2018].

Widdowson, H. G. (1975): Stylistics in the Teaching of Literature, Oxford, Oxford University Press.

Zhang, Yan (2010): “Cooperative Language Learning and Foreign Language Learning and Teaching” [en línea], Journal of Language Teaching and Research, 1, 81-83. http://www. academypublication.com/issues/past/jltr/vol01/01/12.pdf [Consulta: 20 abril 2018], DOI:10.4304/jltr.1.1.81-83. 


\section{Anexo I}

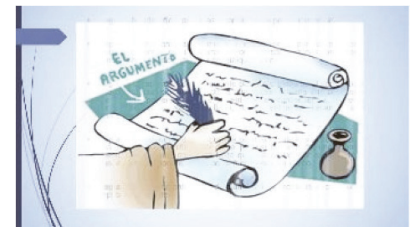

¿Sabéis de qué trata el Quijote? Para conocer su argumento leed el siguiente texto e indicad si las siguientes afirmaciones son verdaderas o falsas. Corregid las falsas y, en el caso de las verdaderas, subrayad los pasajes de texto en donde habéis encontrado la información:

El caballero manchego don Alonso Quijano, llamado por sus vecinos el Bueno, se vuelve loco leyendo novelas de caballerías. Decide salir en busca de aventuras, guiado por nobles ideales: proteger a los débiles, destruir el mal y merecer a Dulcinea del Toboso, que es una campesina idealizada por él. Con armas absurdas y un viejo caballo, Rocinante, sale por La Mancha (una región española) y se hace nombrar caballero en una venta ${ }^{17}$ que él cree que es un castillo, entre las burlas del ventero ${ }^{18}$ y las chicas que trabajan allí. Se hace llamar a partir de entonces Don Quijote de La Mancha. Libera a un muchacho a quien su amo está golpeando por perderle las ovejas (pero en cuanto se marcha, prosigue la paliza); unos comerciantes lo golpean brutalmente Un conocido le recoge y le devuelve a la aldea. Ya recuperado, convence a un rudo labrador, Sancho Panza, ofreciéndole riquezas y poder para que lo acompañe en sus aventuras. Y casi siempre sale mal parado: es golpeado por unos hombres, libera a unos criminales que luego le tiran piedras Sus amigos el cura y el barbero salen en su busca y lo llevan engañado a su pueblo metido en una jaula, dentro de la cual sufre la burla de sus vecinos.

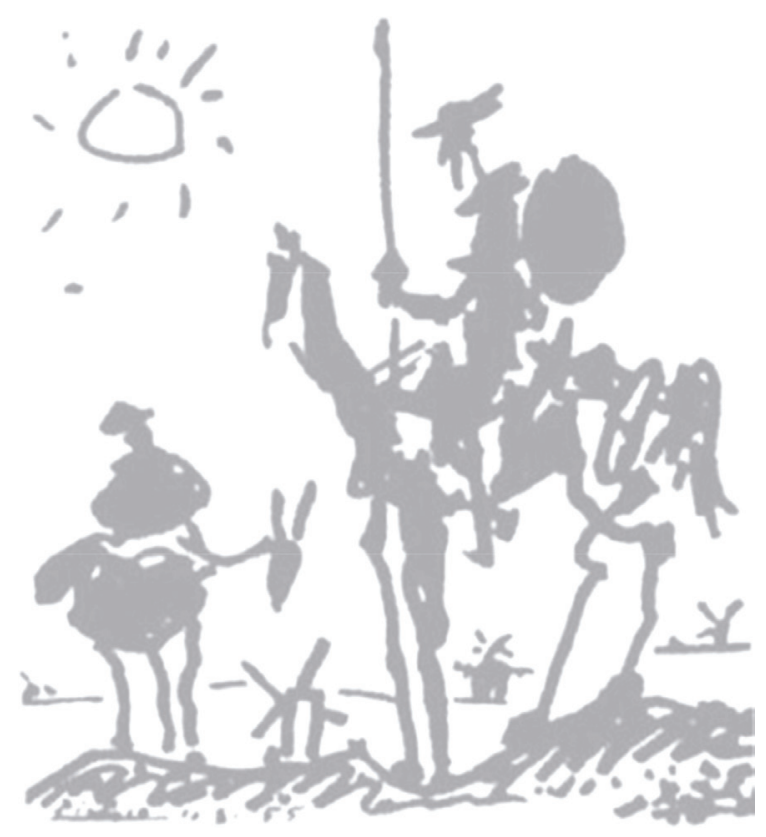

17 La venta era un establecimiento en los caminos en el que se alojaban las personas que hacían viajes más o menos largos.

18 El ventero era el dueño de una venta. 
En la segunda parte don Quijote, obstinado en su locura, sale otra vez acompañado de Sancho Panza. En sus aventuras por tierras de Aragón los dos llegan a los territorios de unos duques, que se burlan de la locura de don Quijote y de la ambición de Sancho Panza. Mandan a este como gobernador a uno de sus territorios con el objetivo de reírse de él, pero lo cierto es que demuestra un gran sentido común. Sancho Panza se cansa de la vida de palacio y don Quijote y él se marchan a Barcelona. Allí es vencido por el Caballero de la Blanca Luna, que en realidad es su amigo Sansón Carrasco, que se ha disfrazado de caballero para intentar que don Quijote vuelva a su casa y recupere su cordura. Sansón Carrasco, vencedor, le impone la obligación de regresar a su pueblo. Don Quijote, física y moralmente derrotado, vuelve a su hogar y allí muere después de haberse curado de su locura.

(Texto adaptado de Literatura española, Fernando Lázaro Carreter y Vicente Tusón, Madrid: Anaya).
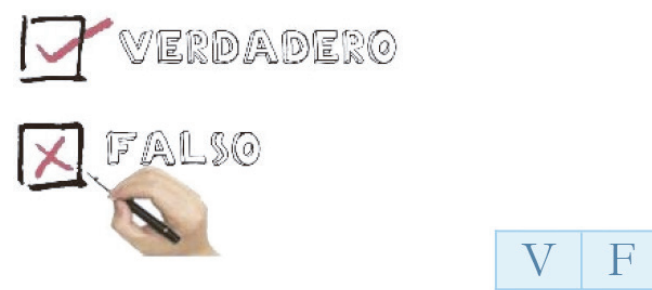

a. Alonso Quijano se hace ordenar caballero porque es muy avaricioso y desea ganar mucho dinero.

\begin{tabular}{|l|l|}
\hline $\mathrm{V}$ & $\mathrm{F}$ \\
\hline
\end{tabular}

b. Normalmente Don Quijote no tiene éxito en sus aventuras.

\begin{tabular}{|l|l|}
\hline $\mathrm{V}$ & $\mathrm{F}$ \\
\hline
\end{tabular}

c. Don Quijote convence a Sancho Panza para que le acompañe en sus aventuras prometiéndole que conseguirá el amor de una dama.

\begin{tabular}{|l|l|}
\hline $\mathrm{V}$ & $\mathrm{F}$ \\
\hline
\end{tabular}

d. Don Quijote no recupera nunca la cordura.

\begin{tabular}{|l|l|}
\hline $\mathrm{V}$ & $\mathrm{F}$ \\
\hline
\end{tabular}

e. Sancho Panza es bastante eficiente como gobernante.

$$
\begin{array}{|l|l|}
\hline \mathrm{V} & \mathrm{F} \\
\hline
\end{array}
$$

f. Don Quijote se cansa finalmente de tanta aventura y regresa voluntariamente a su pueblo. 


\section{Anexo II}

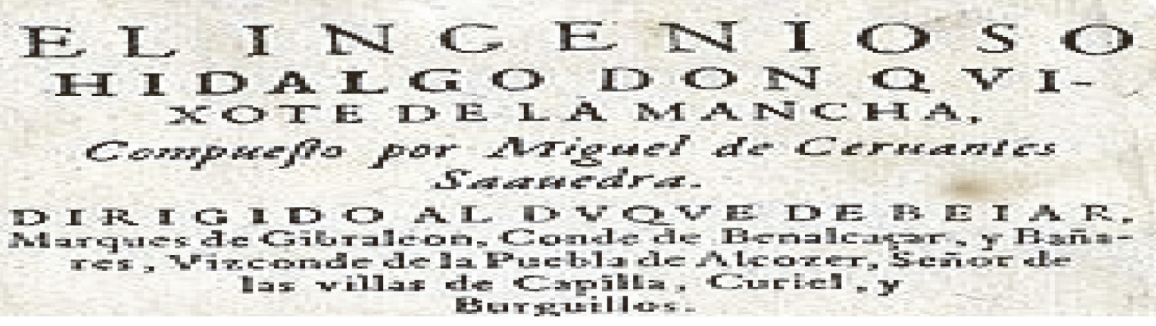

1. Escribid un título alternativo para el episodio que habéis leído, intentando que sea sugerente.

2. Haced un breve resumen del episodio que habéis leído.

3. ¿Cómo justifica Don Quijote el haber "luchado" finalmente contra molinos de viento y no contra gigantes?

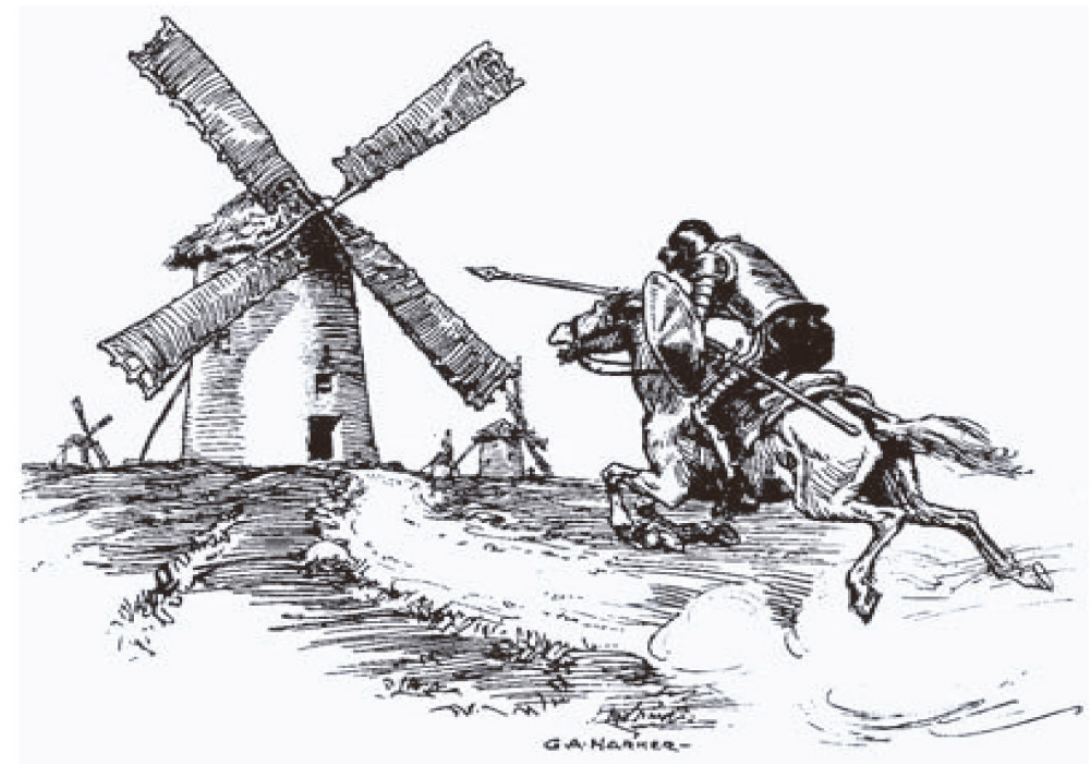

4. En español existe la expresión luchar o combatir contra molinos de viento, que está íntimamente relacionada con lo sucedido en el episodio que acabáis de leer. ¿Cuál creéis que puede ser su significado? Aquí tenéis algunos ejemplos de la lengua actual que os pueden ayudar:

Para muchas personas, luchar contra la corrupción es luchar contra molinos de viento. Resulta casi imposible.

Luchar contra la contaminación es muchas veces luchar contra molinos de viento, porque casi nadie está dispuesto a usar menos su coche. 
* ¿Qué aspectos consideráis que supone, en la sociedad actual, luchar o combatir contra molinos de viento?
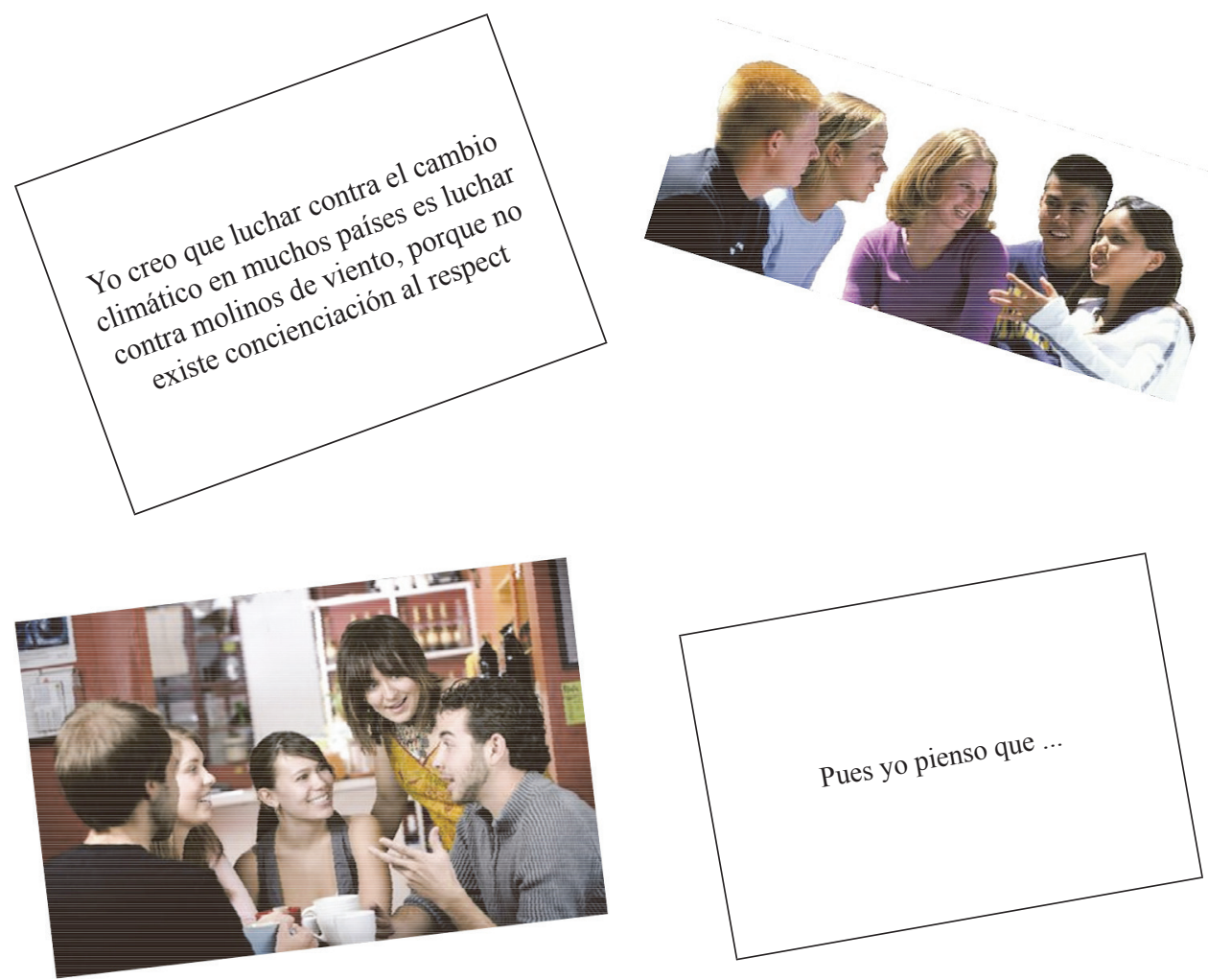

* ¿Y la expresión ser un quijote o sentirse como un quijote? ¿Qué creéis que significa?
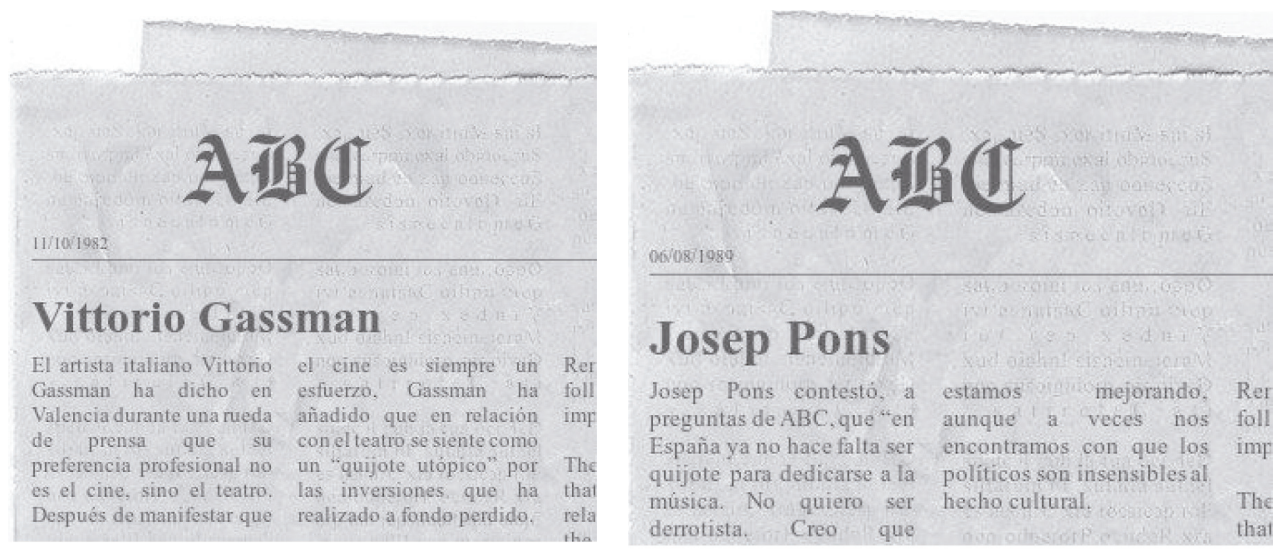
$*$

¿Os habéis sentido alguna vez como un quijote? ¿En qué situaciones?
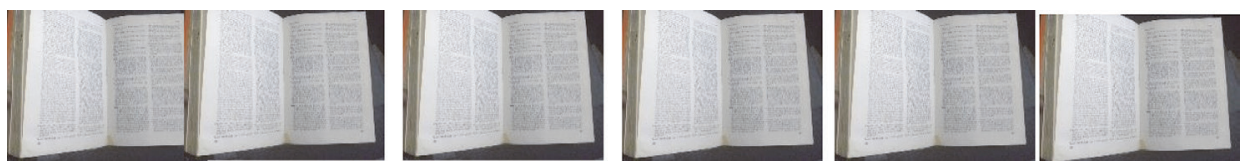

\section{Anexo III}

\section{Expresiones idiomáticas}

1. Como sabéis, en los idiomas hay construcciones casi fijas (las expresiones idiomáticas) que expresan un significado unitario. ¿Podríais poner algunos ejemplos del español? Y en vuestras lenguas, ¿las usáis con frecuencia?

2. El Quijote es una obra muy rica en expresiones idiomáticas. Muchas de ellas se siguen utilizando en la actualidad y se construyen con verbos de uso muy frecuente (caer, llegar, salir ). A continuación hay varios fragmentos del Quijote en los que encontraréis algunas de estas expresiones. Leedlos y relacionad las definiciones de las expresiones con los textos en los que aparecen.

\section{Definiciones}

Textos

1. Dar a conocer algo que estaba oculto

a.

2. Conmover o emocionar

b.

3. Ser oportuno

c.

4. Hacerse público algo que estaba oculto

d.

5. Darse cuenta de algo que antes había pasado inadvertido

e.

6. Tener cualidades muy inferiores a otra persona

f.

a. Se enterneció Sancho Panza con las palabras de maese Pedro y le dijo:

- No llores, maese Pedro, ni te lamentes, que me quiebras el corazón, porque te hago saber que es mi señor don Quijote cristiano tan católico y escrupuloso, que si él cae en la cuenta de que te ha hecho algún agravio, te lo sabrá y te lo querrá pagar y satisfacer con creces.

b. Y oí decir que se decía que me había sacado de casa de mis padres el mozo que vino conmigo, cosa que me llegó al alma, por ver hasta qué punto mi crédito andaba por los suelos, pues no bastaba perderlo con mi venida, sino añadir el con quién, siendo un sujeto tan bajo y tan indigno de mis buenos pensamientos.

c. Gobernador he visto por ahí -dijo Sancho- que a mi parecer no me llega a la suela del zapato, y aun con todo le llaman señoría y le sirven en vajilla de plata.

d. Ese es otro error -replicó don Quijote- en que han caído muchos que no creen que haya habido tales caballeros en el mundo, y yo he procurado sacar a la luz de la verdad este casi común engaño muchas veces con diversas gentes y ocasiones. 
e. No hay más que decir - dijo la duquesa-- Pero si, con todo, hemos de dar crédito a la historia del señor don Quijote que ha salido a la luz del mundo de pocos días a esta parte, con general aplauso de las gentes, de ella se colige, si mal no me acuerdo, que vuesa merced nunca ha visto a la señora Dulcinea, y que esta tal señora no está en el mundo, sino que es dama fantástica, que vuesa merced la engendró y parió en su entendimiento, y la pintó con todas aquellas gracias y perfecciones que quiso.

f. Y si acaso Su Majestad preguntara quién hizo la hazaña, le diréis que el Caballero de los Leones, que de aquí adelante quiero que en este se trueque, cambie, vuelva y mude el que hasta aquí he tenido del Caballero de la Triste Figura. Y en esto sigo la antigua usanza de los caballeros andantes, que se mudaban los nombres cuando querían o cuando les venía a cuento.

3. A continuación fijaos bien en los ejemplos y completad el siguiente cuadro, en el que hay que indicar cómo se construyen las expresiones idiomáticas:

\begin{tabular}{|l|l|l|}
\hline \multicolumn{1}{|c|}{$\begin{array}{c}\text { EXPRESIÓN } \\
\text { IDIOMÁTICA }\end{array}$} & CÓMO SE CONSTRUYE & \multicolumn{1}{c|}{ EJEMPLO } \\
\hline Caer en la cuenta & $\begin{array}{l}\text { Alguien cae en la cuenta } \\
\text { de algo }\end{array}$ & $\begin{array}{l}\text { Don Quijote no cayó en la cuenta de } \\
\text { que eran molinos y no gigantes. }\end{array}$ \\
\hline Llegar al alma & & $\begin{array}{l}\text { La tragedia de esa familia me llegó al } \\
\text { alma. }\end{array}$ \\
\hline No llegar a la suela del & & $\begin{array}{l}\text {-Para mí, el entrenador del Barcelona } \\
\text { no le llega a la suela del zapato al } \\
\text { del Real Madrid. } \\
\text {-Pues para mí es justamente lo } \\
\text { contrario, porque es mucho mejor el } \\
\text { del Barcelona. }\end{array}$ \\
\hline Sacar a la luz & $\begin{array}{l}\text { El periódico en el que trabaja mi } \\
\text { hermana ha sacado a la luz el último } \\
\text { escándalo sobre corrupción política. }\end{array}$ \\
\hline Salir a la luz & $\begin{array}{l}\text { Han salido a la luz nuevas } \\
\text { informaciones sobre el caso de } \\
\text { asesinato que está investigando la } \\
\text { policía. }\end{array}$ \\
\hline Venir a cuento & $\begin{array}{l}\text { Hablar de esta película viene a cuento } \\
\text { porque acaba de obtener el Óscar a la } \\
\text { mejor película extranjera. }\end{array}$ \\
\hline
\end{tabular}

\section{A continuación pensad}

- en algo importante en lo que hayáis caído en la cuenta últimamente;

- una historia que os haya llegado al alma;

- un deportista o un famoso que, en vuestra opinión, no le llega a la suela del zapato a otro;

- un secreto que hayáis sacado a la luz;

19 Vuestra / vuesa merced: forma antigua de usted. 
- una noticia sorprendente o impactante que haya salido a la luz este mes;

- algo que no viene a cuento hacer cuando estáis en la clase de español.

5. Ahora es el momento de que las uséis vosotros. Escribid un diálogo en el que aparezcan al menos tres de las expresiones idiomáticas anteriores. 